\title{
TESTICULAR CYTOPROTECTIVE ACTIVITIES OF CURCUMA LONGA IN STZ-INDUCED DIABETIC ADULT MALE WISTAR RATS
}

\author{
*Olanrewaju A.J, Owolabi J.O. , Olatunji S.Y., Desalu A.B.O. , Amaechi W.C. \\ *Correspondence to AJ Olanrewaju Department of Anatomy, Ben Carson [Snr.] School of Medicine, \\ Babcock University, Nigeria. Phone: +2347038269323, email: afeesjohn@yahoo.com
}

\begin{abstract}
This study was aimed at investigating the cytoprotective activities of Curcuma longa (Turmeric) on the histological structure of the testes in diabetic male rats. Turmeric is commonly called the golden spice, is used as a spice in cooking and also has a long history of medicinal use, dating back nearly 4000 years to the Vedic culture in India. Its major component is the curcumin that is found to be a natural antioxidant. Diabetes affects large number of young men of reproductive age. It is among a number of disorders associated with oxidative stress. There has been a relationship established between the reduction in glucose load and insulin resistance reduction and oxidative stress in people. Male wistar rats $(n=24)$ were allocated randomly into six groups, 4 in each. Group 1: Control were given only water and standard rat chow; Group 2 and 3: turmeric $(100 \mathrm{mg} / \mathrm{kg})$ and $(25 \mathrm{mg} / \mathrm{kg})$ respectively; Group 4: induced with $30 \mathrm{mg} / \mathrm{kg}$ of streptozotocin (STZ) for 3 days; Group 5: STZ with turmeric (100mg/kg); Group 6: STZ with turmeric $(25 \mathrm{mg} / \mathrm{kg})$. At the end of the experiment (21 days), the testes were excised for histological analysis. The seminiferous tubules, seminiferous epithelium, Leydig cells were shown to be enhanced in the histoarchitecture of the testes of the treated diabetic groups and did not show any toxicity on the testes in the non-diabetic groups. In conclusion, this study has shown that turmeric does not only possess a non-toxic effect but has cytoprotective effects on the histoarchitecture of the testes in diabetic rats.

Keywords: histo-architecture, leydig cells, diabetes, oxidative stress, testes, curcumin.
\end{abstract}

\section{INTRODUCTION}

Oxidative stress is a common consequence of diabetes mellitus (Giugliano et al., 1996; FeilletCoudray et al., 1999; Rosen et al., 2001); Diabetic complications associated with oxidative stress include nephropathy, neuropathy, retinopathy, and testicular injury (Sharpe et al., 1998; Greene et al.,1999; $\mathrm{Ha}$ et al., Hinokio et al., 1999).Diabetes-related effects on testicular function have been attributed to the lack of insulin. The regulatory action of this hormone is known, and observations of a direct effect on both Leydig cells (Khan et al, 1992; Hurtado de Catalfo et al, 1998) and Sertoli cells (Borland et al, 1984; Mita et al, 1985) have been reported. Nonetheless, the data are confusing, and the exact role that insulin plays in the regulation of the male reproductive function is still unclear.
Thus, antioxidant therapy is one of the strategies for diabetes treatment. Many herbal extracts or derivatives with high antioxidant activity are useful for treatment of diabetes and other metabolic syndrome (Samad et al., 2009). Several plant extracts are known to have antidiabetic properties and a large number of compounds from plant extracts have been reported to have beneficial effects for the treatment of diabetes mellitus (Ramesh et al., 2010). Diabetes can be managed by diet, exercise and chemotherapy. However, the pharmacological drugs are either too expensive or have undesirable side effects or contraindications (Maiti et al., 2008). Throughout the world, many traditional plant treatments for diabetes exist, and therein lies a hidden wealth of potentially useful natural products for the control of diabetes. Natural plant drugs are frequently

Submitted 16th July 2016, revised on 13th December 2016. Published online 20th February 2017. To cite: Olanrewaju AJ, Owolabi JO. , Olatunji SY, Desalu ABO, Amaechi WC. Testicular cytoprotective activities of curcuma longa in stz-induced diabetic adult male wistar rats Anatomy Journal of Africa. 2017. Vol 6 (1): 905 -913. 
considered to be less toxic and free from side effects than synthetic ones (Sunil et al., 2009; Ramesh et al., 2012).

Turmeric is a product of a rhizomatous herbaceous perennial plant of the ginger family, Zingiberacea and is native to tropical South Asia. There are over 133 species of curcuma worldwide. It is a known antioxidant and is used for both medicinal and household purposes. Its major component is the curcumin that is found to be a natural antioxidant (Tayyem et al, 2012). Out of all the species of the genus Curcuma L., only about 20 species have been studied phytochemically (Nahar et al, 2007).

Curcumin was found to exhibit a variety of biological activities including antitumor (Akanni and Emerole, 2002); antioxidant (Farombi and Nwaokeafor (b), 2005), anti-inflammatory properties and antiviral activities (Nwankwo et al., 2000). The protective effects of curcumin against harzadous chemicals were studied in different animals (Kim et al., 2003; Farombi et al., 2004; Farombi et al.(a), 2005). In the study by Farombi et al. (2007), the results indicated that kolaviron and curcumin protect against testicular oxidative damage induced by di-n-butylphthalate(DBP). The chemoprotective effects of these compounds may be due to their intrinsic antioxidant properties and as such may prove useful in combating phthalateinduced reproductive toxicity. The present study aimed to evaluate the testicular enhancement of curcumin in oxidative stress induced by hyperglycaemia induced reproductive damage in male albino rats.

\section{METHODS}

\section{Experimental Design}

\section{Animal Protocol}

24 Male Wistar rats were purchased from the Babcock university animal house. They were purchased with a body weight of $180 \mathrm{~g}-220 \mathrm{~g}$ and housed in the animal house of the Babcock University, where they were grouped and placed in 6 cages ( 4 animals per cage) under a 12-hour light: dark cycle with food and drink ad libitum. The experiments complied with the guidelines established by the research ethical committee of the department of anatomy, Babcock University.

\section{Diabetes induction}

Diabetes was induced by intraperitoneal injection of streptozotocin for three consecutive days (30 $\mathrm{mg} / \mathrm{kg}$ of body weight) in $0.9 \% \mathrm{NaCl}$ with $100 \mathrm{mM}$ sodium citrate buffer ( $\mathrm{pH}$ 4.5). Diabetes was confirmed on the 4th day after STZ injection by the determination of glucosuria and glycaemia (glucose and glycaemia strips). Both healthy and STZ-diabetic rats were maintained without any other treatment for 3 weeks after diabetes was confirmed in the STZ-injected rats at the beginning of the experiment. Healthy rats were used as control, while some other healthy rats received additional treatment of Turmeric.

\section{Oral treatment with Turmeric}

During 3-week period, the animals were treated with Turmeric using oral canula with the regimen below;

Group 1 is the control group which received no treatment,

While Groups 2 to 6 (except group 4) were treated with graded dose of turmeric thus;

Group 2: rats received high dose turmeric (100mg/kg) daily;

Group 3: rats received low dose turmeric (25mg/kg) daily;

Group 4: rats were induced with $30 \mathrm{mg} / \mathrm{kg}$ of STZ intraperitoneally for 3 days;

Group 5: rats were induced with STZ $(30 \mathrm{mg} / \mathrm{kg})$ intraperitoneally for 3 days with high dose turmeric $(100 \mathrm{mg} / \mathrm{kg})$ daily;

Group 6: rats were induced with STZ (30mg/kg) intraperitoneally for 3 days with low dose turmeric $(25 \mathrm{mg} / \mathrm{kg})$ daily.

At the end of the experiment, the animals were anesthetized with diethyl ether and sacrificed by decapitation after 21days of administration. Testes and adjacent epididymis were weighed and then processed in 2 ways:

Tissues were immediately fixed in $3 \%$ formaldehyde in a buffered solution containing 54 
$\mathrm{mM} \mathrm{NaH} \mathrm{PO}_{4}$ and $28 \mathrm{mM} \mathrm{Na}_{2} \mathrm{HPO}_{4}(\mathrm{pH} \mathrm{7.4})$ at $4{ }^{\circ} \mathrm{C}$ (buffered formaldehyde) and processed and therefore sectioned at $5 \mu \mathrm{m}$ with the aid of the rotary microtome and then processed for light microscopy by the Haematoxylin and Eosin ( $\mathrm{H}$ \& E) and Van Gieson (VG) for histological demonstration.

\section{RESULT}

The aim of the present study was to evaluate the testicular enhancement properties of the aqueous extract of Curcuma longa in streptozotocin-induced type 1 diabetic rats. Streptozotocin-induced type 1 diabetes in rats provides a relevant model to study the reproductive dysfunction under diabetic conditions, as they exhibit a number of reproductive deficits that resemble those seen in human diabetics (Soudamani et al., 2005). It is well known that diabetes is positively associated with lowered male fertility and sexual dysfunction as it causes oxidative damage to the testicular tissue (Shalaby and Mouneir, 2010). The figures 1 and 7 represent the control groups ( $H \&$ E and VG respectively), while the Figures 26 (for $H$ \& $E$ ) and 8-12 (VG) illustrate the histological examination of testicular tissues of different treatment groups.

Testicular histology of control group [fig. $1 a ; b$ and $7 a ; b]$ revealed normal spermatogenesis, depicting all the germ cells (seminiferous epithelium) types, viz. spermatogenic, primary spermatocytes and spermatogonia with normal morphology, size and volume of the seminiferous tubules.

The Sertoli and interstitial cells of Leydig also showed normal morphology in size, shape, and number all the photomicrographs of the control group as well.

Moreover, all layers of germ cells had normal basement membrane and interstitial tissue as demonstrated by the Van Gieson stain showing the collagen fibres in figures 7.

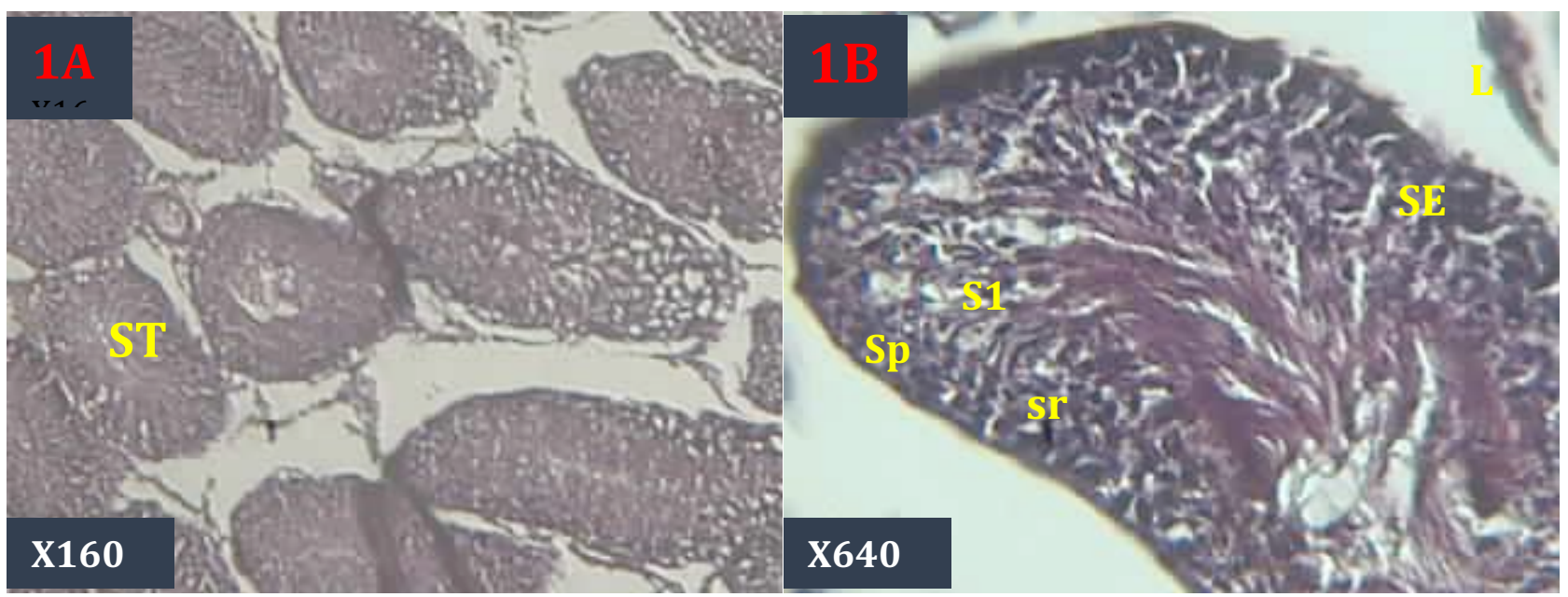

Figure 1: Photomicrographs of the testis of the Control Groupshowing in $[A]$ the seminiferous tubules [ST], and in [B] the seminiferous epithelium [SE] and the Leydig cells [L], sertoli cells[sr], spermatogonia[sp] and primary spermatocyte[s1] [H\&E] 


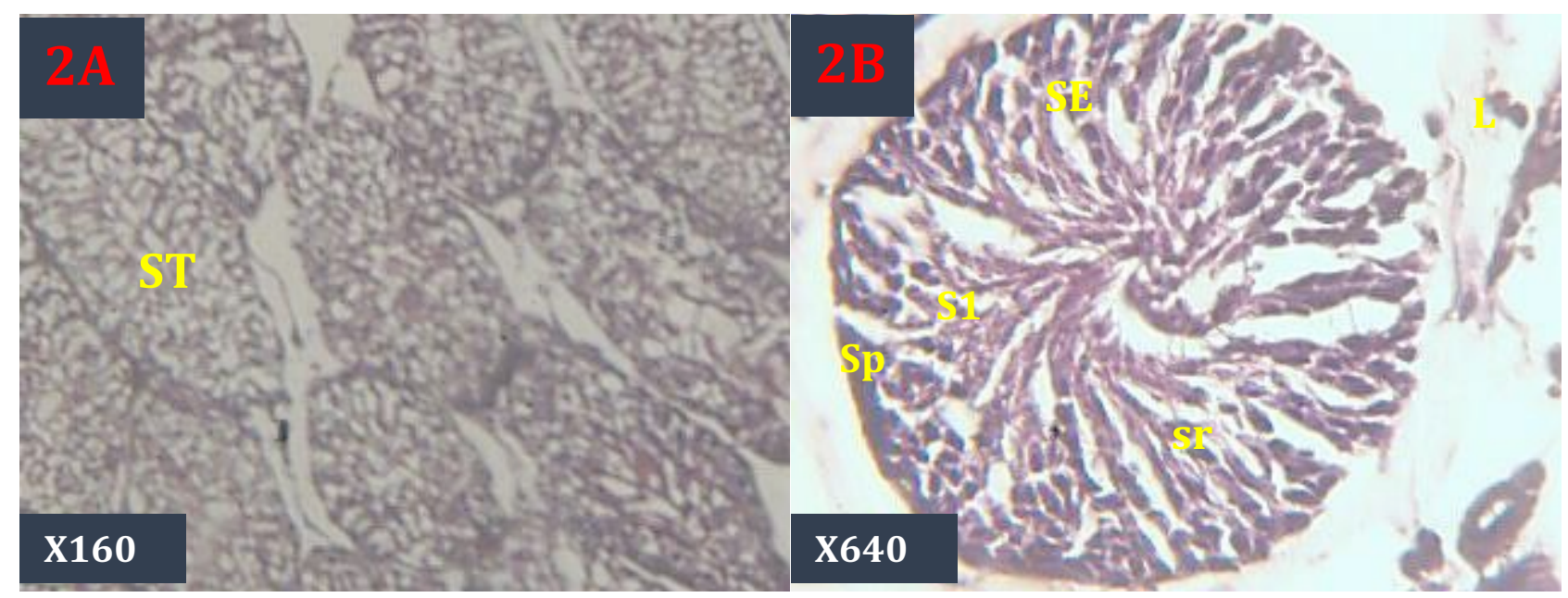

Figure 2: Photomicrographs of the testis of the high dose turmeric group 2 animals showing in $[A]$ the seminiferous tubules [ST], and in [B] the seminiferous epithelium [SE] and the Leydig cells [L], sertoli cells[sr], spermatogonia[sp] and primary spermatocyte[s1] [H\&E]

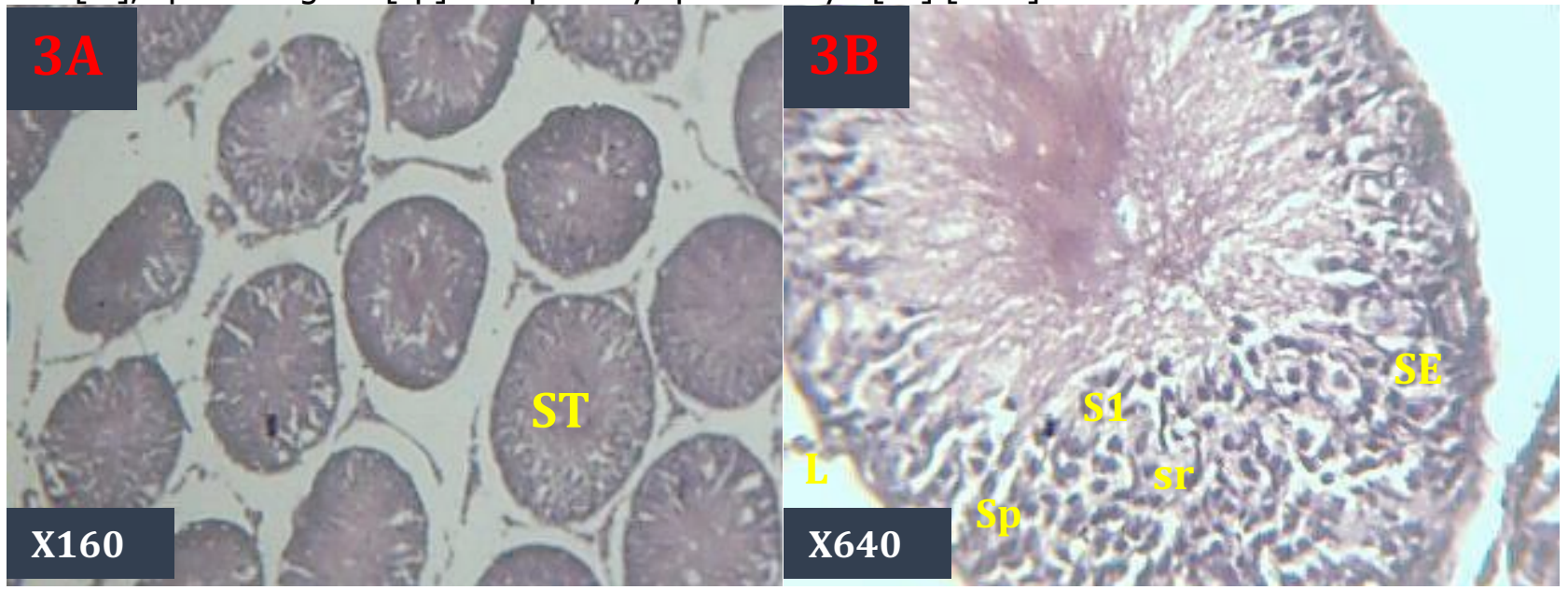

Figure 3: Photomicrographs of the testis of the low dose turmeric group 3 animalsshowing in $[A]$ the seminiferous tubules [ST], and in [B] the seminiferous epithelium [SE] and the Leydig cells [L], sertoli cells[sr], spermatogonia[sp] and primary spermatocyte[s1] [H\&E]

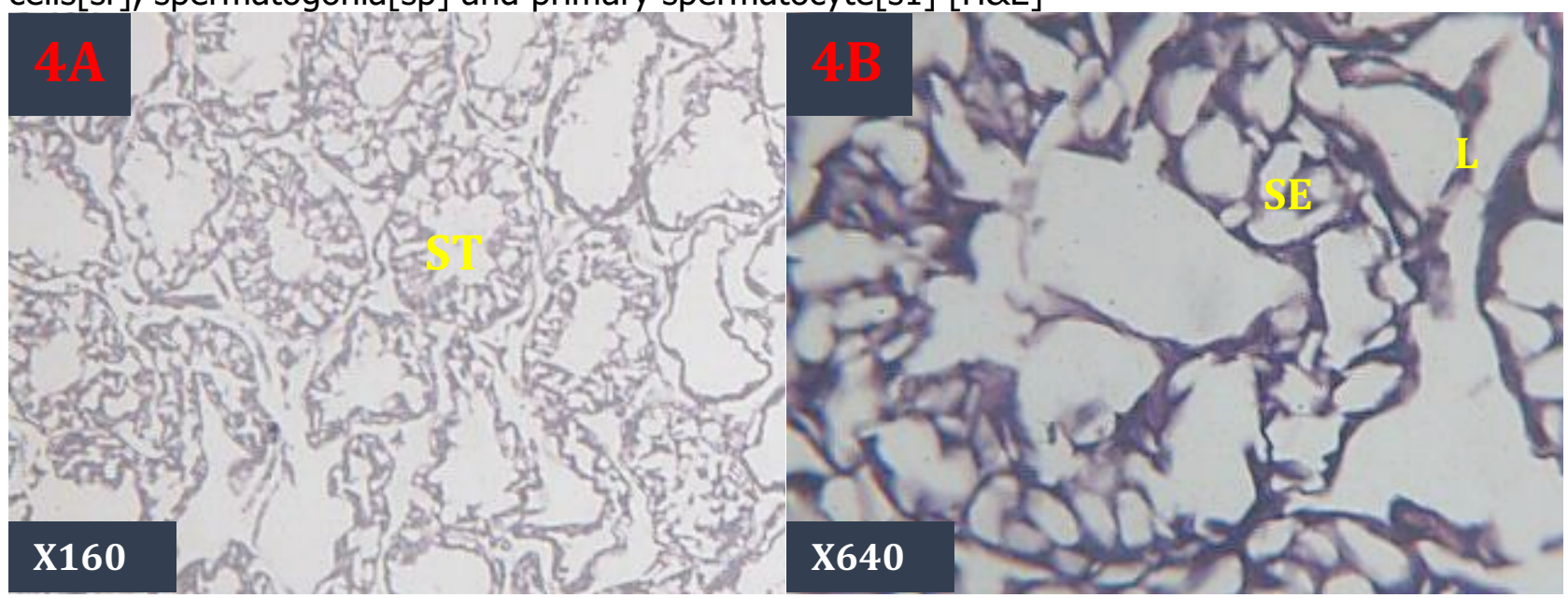


Figure 4: Photomicrographs of the testis of the STZ induced diabetes group showing in $[A]$ the seminiferous tubules [ST], and in [B] the seminiferous epithelium [SE] and the Leydig cells [L], with no sertoli cells[sr], spermatogonia[sp] and primary spermatocyte[s1] [H\&E]

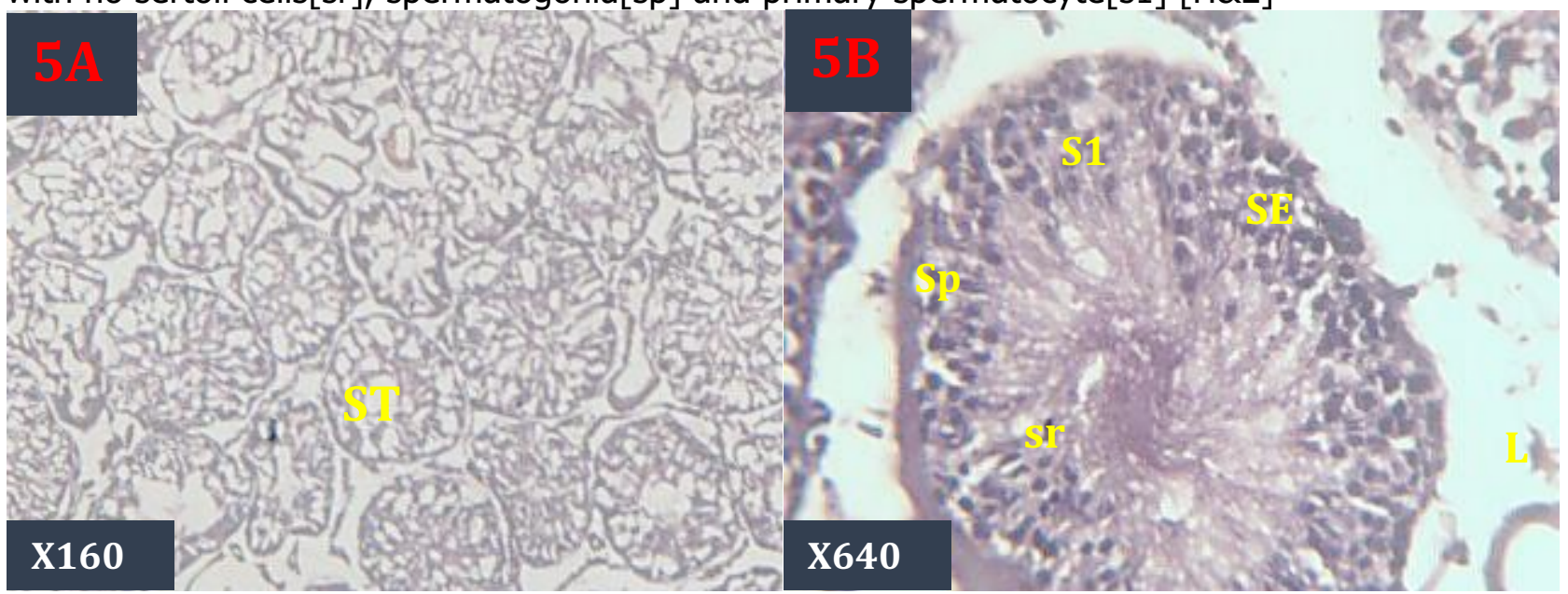

Figure 6: Photomicrographs of the testis of the STZ induced diabetes + low dose turmeric group showing in $[\mathrm{A}]$ the seminiferous tubules $[\mathrm{ST}]$, and in $[\mathrm{B}]$ the seminiferous epithelium [SE] and the Leydig cells [L], sertoli cells[sr], spermatogonia[sp] and primary spermatocyte[s1] [H\&E]

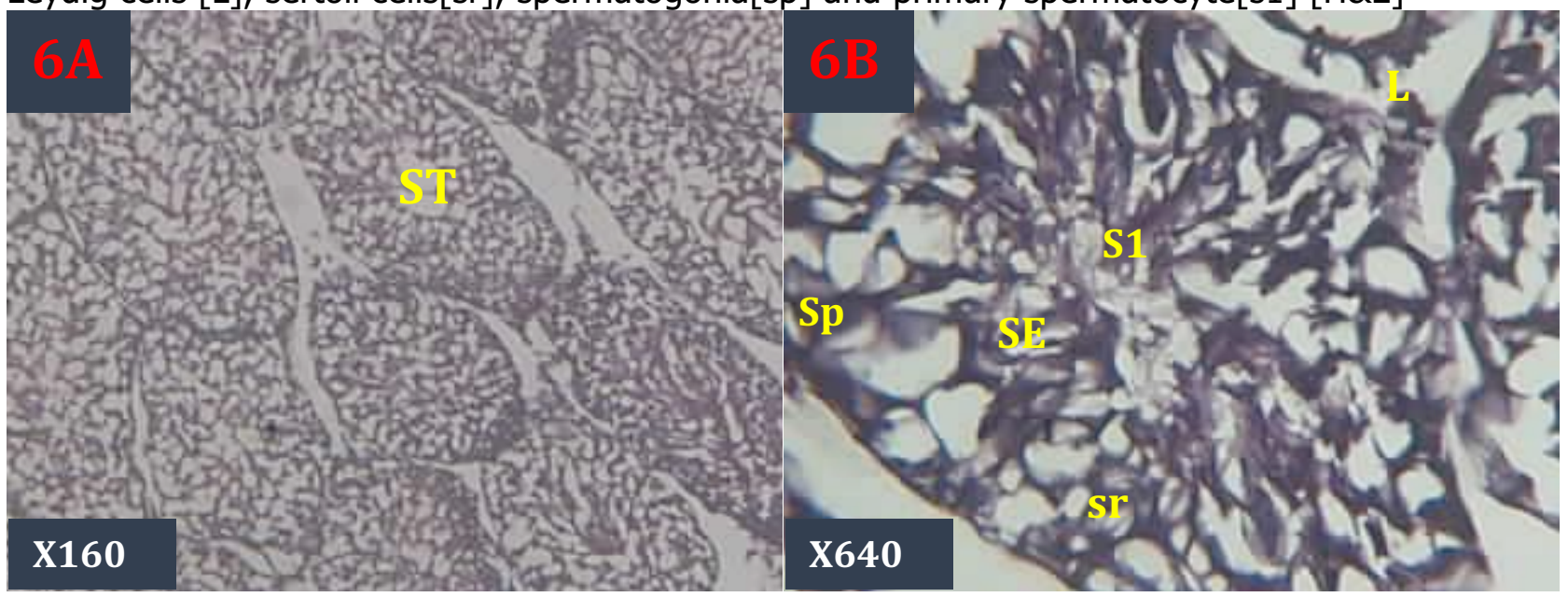

Figure 6: Photomicrographs of the testis of the STZ induced diabetes + high dose turmeric group showing in $[\mathrm{A}]$ the seminiferous tubules $[\mathrm{ST}]$, and in $[\mathrm{B}]$ the seminiferous epithelium [SE] and the Leydig cells [L], sertoli cells[sr], spermatogonia[sp] and primary spermatocyte[s1] [H\&E] 


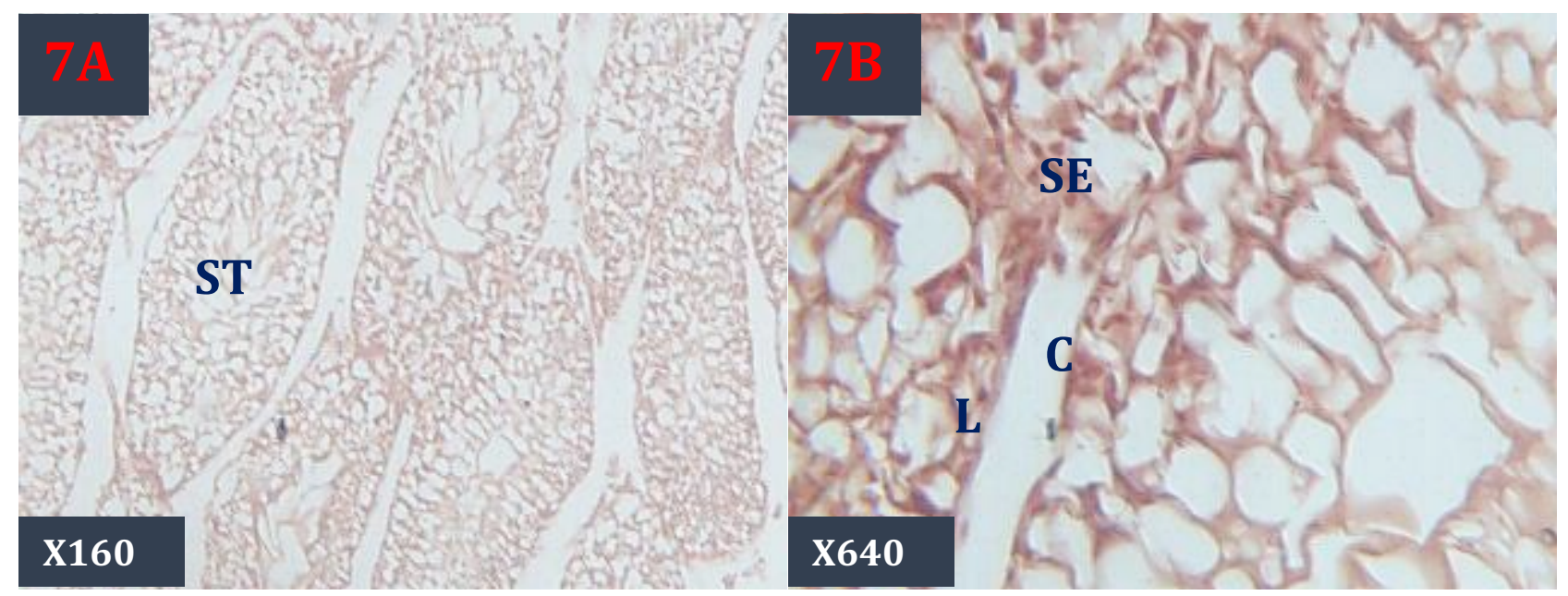

Figure 7: Photomicrographs of the testis of the Control group showing the seminiferous tubules [ST, A] and the seminiferous epithelium [SE, B], the Leydig cells [L] and collagen fibre (C) [VG].

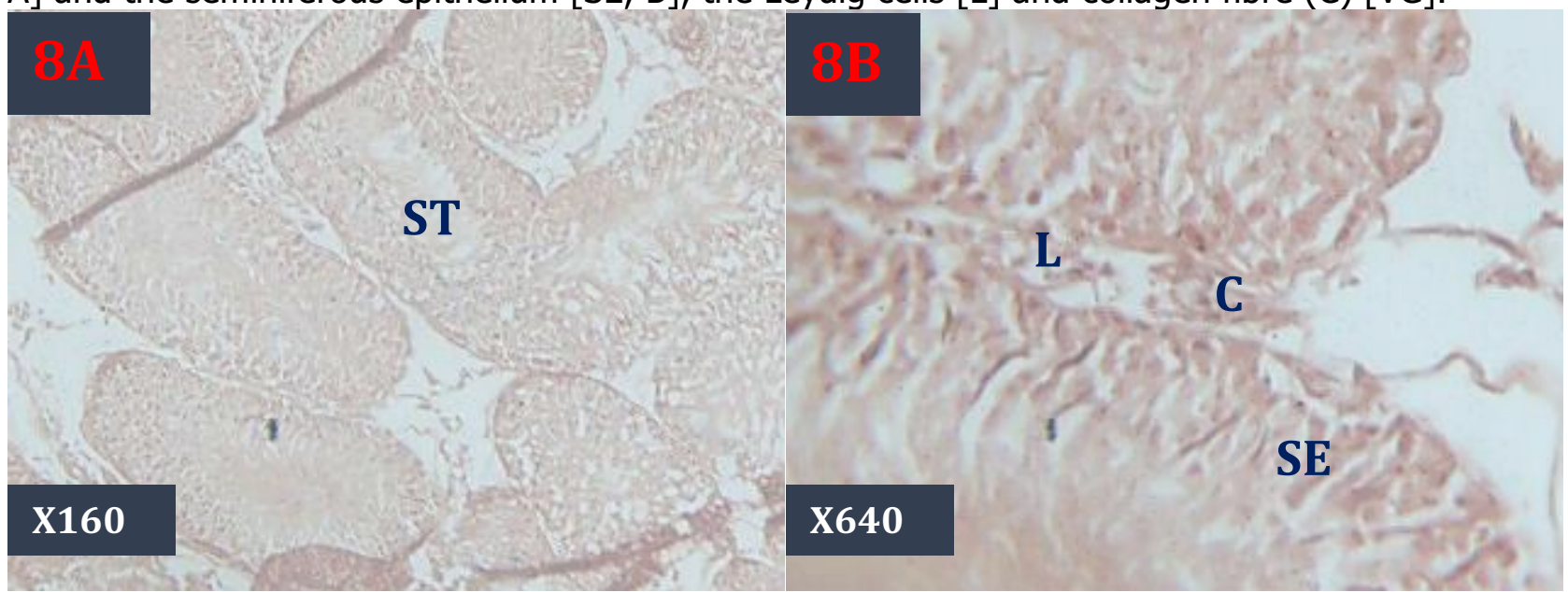

Figure 8: Photomicrographs of the testis of the high dose turmeric group showing the seminiferous tubules [ST, A] the seminiferous epithelium [SE, B], the Leydig cells [L]and collagen fibre (C) [VG].

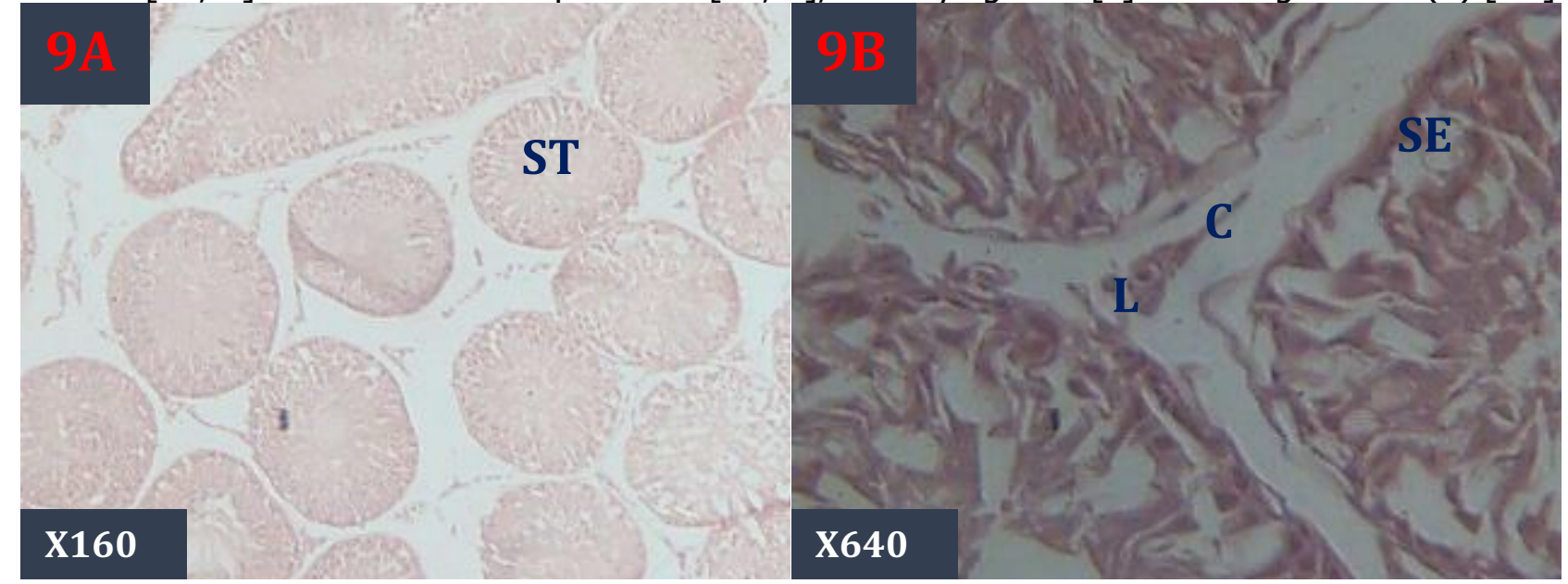

Figure 9: Photomicrographs of the testis of the low dose turmeric group 3 animals showing the seminiferous tubules [ST, A] and the seminiferous epithelium [SE, B]. and collagen fibre (C) [VG]. 


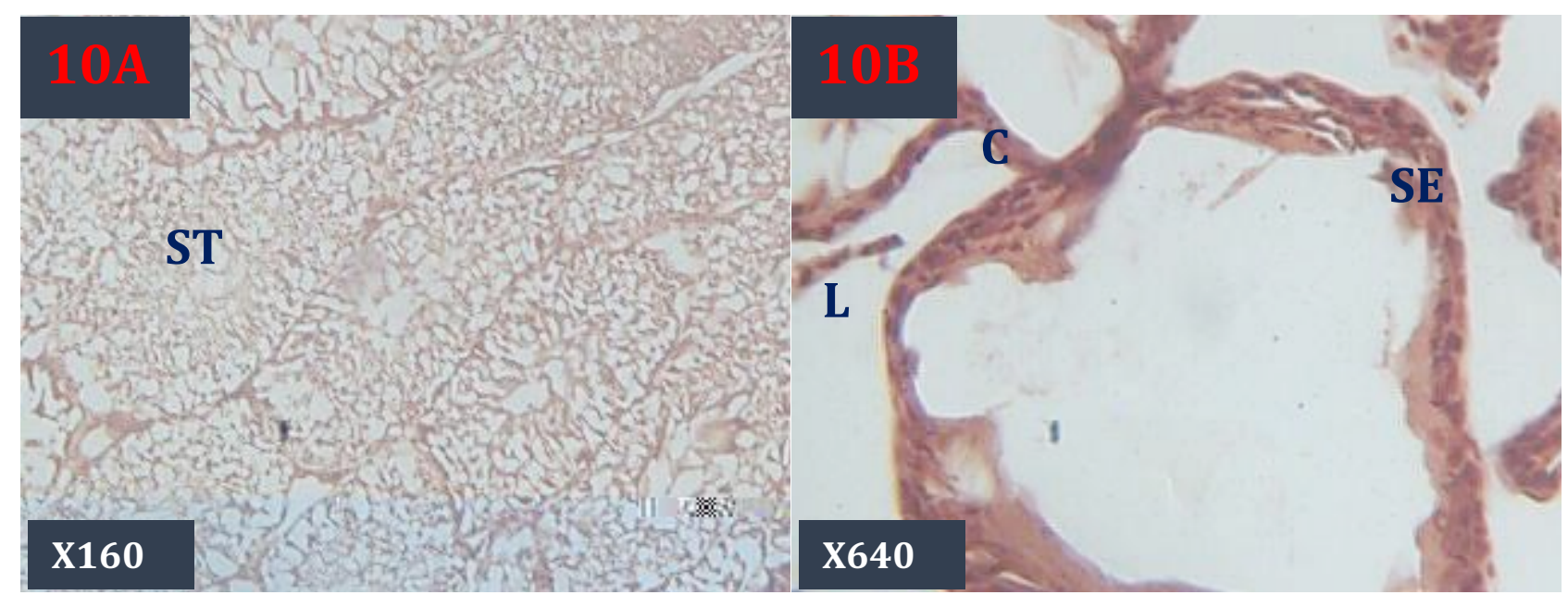

Figure 10: Photomicrographs of the testis of the STZ induced diabetes group 4 animals showing the seminiferous tubules [ST, A] and the seminiferous epithelium [SE, B] and collagen fibre(C) [VG]

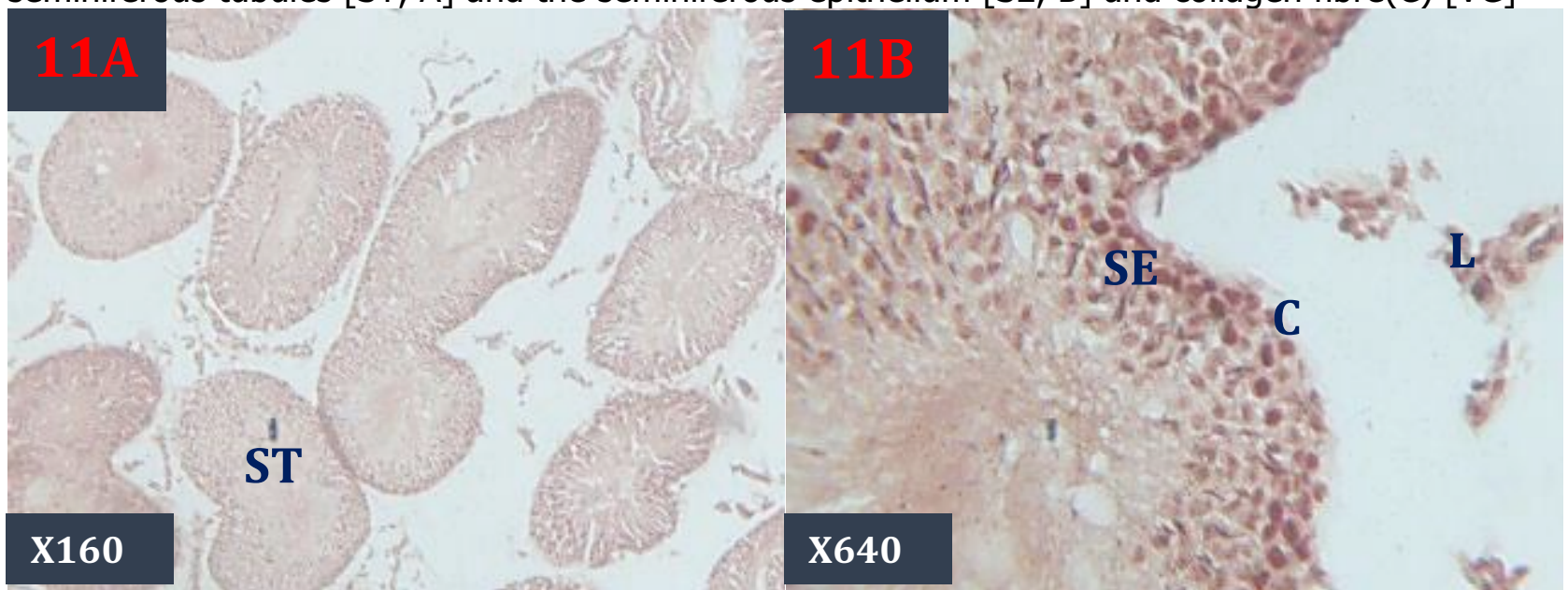

Figure 11: Photomicrographs of the testis of the STZ induced diabetes + high dose turmeric group 6 animals showing the seminiferous tubules $[\mathrm{ST}, \mathrm{A}]$ the seminiferous epithelium $[\mathrm{SE}, \mathrm{B}]$ and the Leydig cells [LC] and collagen fibre (C) [VG]

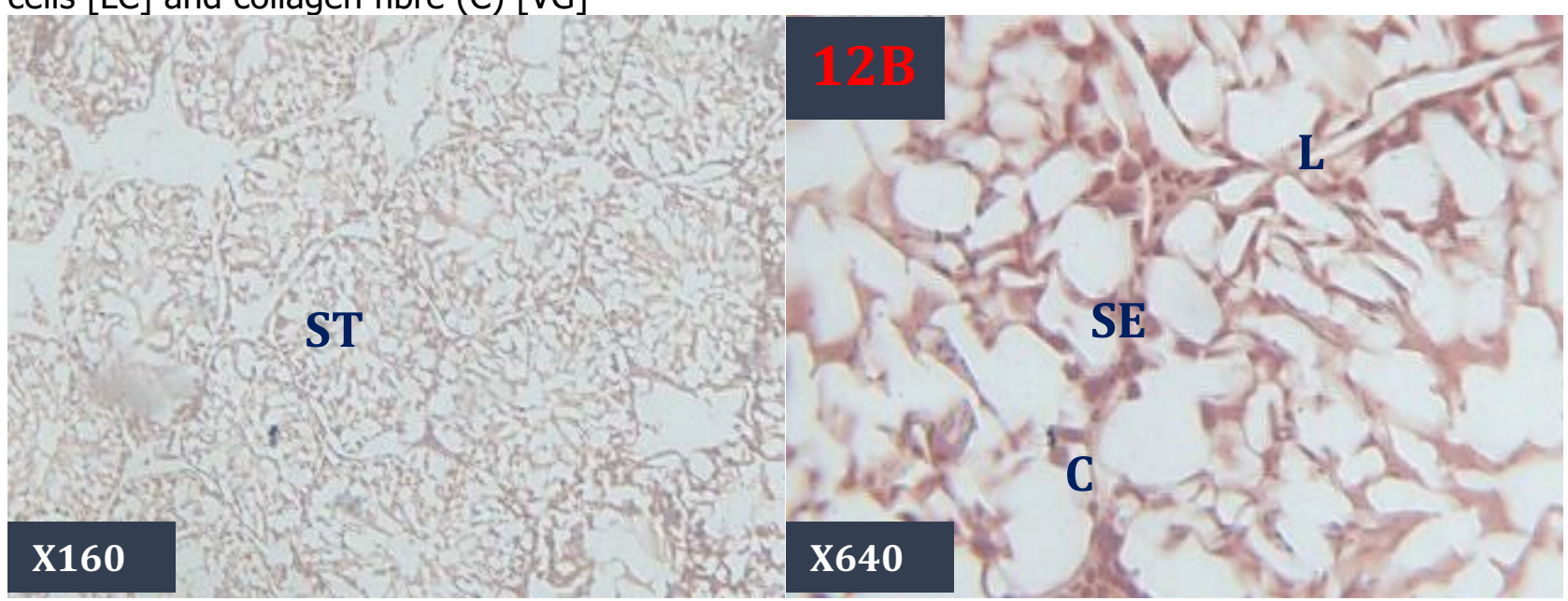

Figure 12: Photomicrographs of the testis of the STZ induced diabetes +low dose turmeric group 5 animals showing the seminiferous tubules $[\mathrm{ST}, \mathrm{A}]$ and the seminiferous epithelium $[\mathrm{SE}, \mathrm{B}]$. and collagen fibre (C) [VG] 
Anatomy Journal of Africa. 2017. Vol 6 (1): 905 -913

\section{DISCUSSION}

The figures $2 a ; b$ and $3 a ; b$ as well indicate normal testis of rats treated separately with turmeric low dose and high dose, respectively. It definitely shows proliferation of spermatogenic cells, rapid maturation of seminiferous epithelium

Figure $4 a$; b demonstrates that diabetes caused degenerative changes such as loss of germ cells, abnormality of germinative epithelium, interruption in meiosis, sperm with abnormal shape and concentration of cells.

These changes were markedly reduced with oral administration of turmeric extract, revealing a marked repairing of testicular abnormalities, as shown in Figure $6 \mathrm{a} ; \mathrm{b}$ especially with the high dose group show rapid regenerative effects, in figure $5 a$; b demonstrating maximum antioxidant and healing effects against STZ induced diabetes testicular damage, showing sperm with normal morphology and concentration close to the control group. Histopathological findings are in accordance with the results of the above studied parameters for testicular toxicity.

Histopathological changes revealed marked degeneration of most seminiferous tubules including atrophied seminiferous tubules with absence of spermatogenic series and sperms in tubular lumen (Figure 4a,b; 10a,b) and decrease in both diameter of seminiferous tubules and height of germinal epithelium of testes as compared to those in the normal controls. These changes may be due to DM which induces subtle molecular changes that are important for sperm quality and function and alters conventional sperm parameters. Various mechanisms may explain the sperm damage observed in patients with DM. These include endocrine disorders, neuropathy, and increased oxidative stress ( $\mathrm{La}$ Vignera et al., 2012). These effects may due to DM decreases serum testosterone levels
(Shalaby and Mouneir, 2010; Maiorino et al., 2014) which are associated with a steroidogenetic defect in Leydig cells. Furthermore, DM is associated with an increased oxidative stress, which damages sperm nuclear and mitochondrial DNA. Finally, spermatogenesis derangement and germ cell apoptosis in type $1 \mathrm{DM}$ may relate to a local autoimmune damage, whereas insulin resistance, obesity, and other related comorbidities may impair sperm parameters and decrease testosterone serum levels in patients with Type 2 DM (La Vignera et al., 2012). Oral administration of the Curcuma longa to the diabetic rats for 21-days caused enhancement of the histological changes of testes besides enhancing the diameter of seminiferous tubules, and height of epithelium of testes. These results indicate that extract of Curcuma longa used in this study act to attenuate the degenerative changes in testes because it contains many compounds that act separately or synergistically to enhance testes function and retard normal value. This may be due to the presence of some phytochemical compounds such as saponin, flavones, tannins and terpenes and its action can be related to insulin-like action and had ability to induce DNA repair systems due to antioxidant activities which reduce or prevent generation of free radicals.

In conclusion, it is obvious that the Curcuma longa as revealed in many other previous investigation using the plant as treatment, is a preferred and potential agent for the enhancement of the testes of diabetic rat model in which oxidative stress is induced; this could be a possible therapeutic treatment with a welldefined dosage in human male subjects, who have difficulty with fertility.

\section{REFERENCES}


1. Farombi EO, Adepoju BF, Ola-Davies OE, Emerole GO. (a) 2005. Chemoprevention of aflatoxin B1induced genotoxicity and hepatic oxidative damage in rats by Kolaviron, a natural biflavonoid of Garcinia kola seeds. Eur J Cancer Prev; 14: 207-14.

2. Farombi EO, Akanni OO, Emerole GO. 2002. Antioxidative and scavenging activities of kolaviron in vitro. Pharm Biol; 40: 107-16.

3. Farombi EO, Moller P, Dragsted LO. 2004. Ex vivo and in vivo protective effects of kolaviron against oxygen derived radical-induced DNA damage and oxidative stress in human lymphocytes and rat liver cells. Cell Biol Toxicol; 20: 71-82.

4. Farombi EO, Nwaokeafor IA. (b) 2005. Anti-oxidant mechanisms of action of kolaviron: studies on serum lipoprotein oxidation, metal chelation and oxidative microsomal membrane damage in rats. Clin Exp Pharmacol Physiol; 32: 667-74.

5. Farombi EO, Abarikwu SO, Adedara IA and Oyeyemi MO. 2007. Curcumin and kolaviron ameliorate di-n butylphthalate-induced testicular damage in rats. Basic Clin Pharmacol Toxicol, 100: 43-8.

6. Feillet-Coudray C, Rock, E, Coudray C, Grzelkowska K, Azais-Braesco V, Dardevet D, and Mazur A. 1999. Lipid peroxidation and antioxidant status in experimental diabetes. Clin. Chim. Acta, 284: 3143.

7. Rosen P, Nawroth PP, King G, Moller W, Tritschler HJ, and Packer L. 2001. The role of oxidative stress in the onset and progression of diabetes and its complications: A summary of a Congress Series sponsored by UNESCO-MCBN, the American Diabetes Association and German Diabetes Society. Diabetes Metab. Res. Rev., 17: 189-212.

8. Giugliano, D, Ceriello A, and Paolisso G. 1996 Oxidative stress and diabetic vascular complications. Diabetes Care, 19: 257-263.

9. Greene, DA, Stevens, MJ, Obrosova I, and Feldman, EL. 1999. Glucose-induced oxidative stress and programmed cell death in diabetic neuropathy. Eur. J. Pharmacol., 375: 217- 223.

10. $\mathrm{Ha} \mathrm{H}$, and Kim KH. 1999. Pathogenesis of diabetic nephropathy: The role of oxidative stress and protein kinase C. Diabetes Res. Clin. Pract., 45: 147-151.

11. Hinokio Y, Suzuki S, Hirai M, Chiba M, Hirai A, and Toyota T. 1999. Oxidative DNA damage in diabetes mellitus: Its association with diabetic complications. Diabetologia, 42: 995- 998.

12. Khan S, Teerds K, Dorrington J. 1992. Growth factor requirements for DNA synthesis by Leydig cells from the immature rat. Biol Reprod.; 46: 335-341.

13. Kim JE, Kim AR, Chung HY, Han SY, Kim BS, Choi JS. 2003. In vitro peroxynitrite scavenging activity of diarylheptanoids from Curcuma longa. Phytother Res; 17: 481-4.

14. Mita M, Borland K, Price JM, Hall PF. 1985. The influence of insulin and insulin-like growth factor-I on hexose transport by Sertoli cells. Endocrinology. ;116: 987-992.

15. Nahar L., Sarker SD. 2007: Phytochemistry of the genus Curcuma. In turmeric. ; pp 71-106.

16. Nwankwo JO, Tanhnteng JG, Emerole GO. 2000. Inhibition of aflatoxin B1 genotoxicity in human liver-derived HepG2 cells by kolaviron biflavonoids and molecular mechanisms of action. Eur J Cancer Prev;9: 351-61.

17. Tayyem RF, Health DD, AI-Delaimy WK Rock CL. 2012: Curcumin content of turmeric and curry powders. Nutr cancer 55 2: 126-131. 